\title{
A dupla face da liberdade: o liberto na sociedade romana
}

\author{
Fábio Duarte Joly*
}

Mouritsen, Henrik. The freedman in the Roman world. Cambridge: Cambridge University Press, 2011.

A publicação do livro de Henrik Mouritsen, professor de história romana no King's College de Londres, sobre os libertos na sociedade romana vem cobrir uma lacuna nos estudos de história social romana em geral e sobre escravidáo romana em particular. Isso pode soar à primeira vista um tanto curioso já que a figura do ex-escravo é ubíqua na literatura latina desde o período republicano até a Antiguidade Tardia, e sobretudo na epigrafia alto-imperial. Mas, embora essa ubiquidade seja reconhecida e citada pela bibliografia especializada, há uma notável carência de análises exclusivamente voltadas para o papel social, político e econômico dos libertos em Roma. Para se ter uma ideia desse fato basta lembrar que data de 1928 o livro de A. M. Duff, Freedmen in the Early Roman Empire (Cambridge: W. Heffer \& Sons); de 1969, o livro de Susan Treggiari, Roman freedmen during the late Republic (Oxford: Clarendon Press); e de 1981 o estudo de Georges Fabre, Libertus: patrons et affranchis à Rome (Roma: École Française de Rome), também com foco na República.

A contribuição de Mouritsen é, portanto, muito bem-vinda, pois, além de cobrir tanto o período republicano quanto o imperial, revela certa reorientação dos estudos sobre escravidáo antiga nos últimos 10 anos rumo à valorização da figura do liberto na sociedade greco-romana, como testemunham a recente coletânea organizada por Sinclair Bell e Teresa Ramsby, Free at last! The impact of freed slaves on the Roman Empire (London: Bristol Classical Press, 2012) e o livro de R. Zelnick-Abramovitz sobre a manumissão no mundo grego (Not wholly free: the concept of manumission and the status of manumitted slaves in the ancient Greek world. Leiden: Brill, 2006).

Essa mudança de ótica indica assim que escravidão e manumissão estão deixando de ser tomadas como fenômenos separados, visão esta muitas vezes reforçada por um entendimento da libertação do escravo como tendo um efeito desestruturante numa sociedade escravista (pressuposto da historiografia produzida nas décadas de 1920 e 1930, como o estudo de Duff, que associa manumissáo e degeneraçáo racial do povo romano). Significa também uma crítica ao legado abolicionista dos séculos XVIII e XIX que moldou nossa compreensão da escravidão antiga, que, com sua ênfase na violência e na desumanidade da instituição, inibiu estudos que colocassem em cena o liberto, personagem que poderia mitigar o lado cruel da escravidão ao mostrá-la como

Resenha - DOI - http://dx.doi.org/10.1590/2237-101X014027013 
um estado transitório, que comprometeria a formação de uma solidariedade de classe entre os escravizados.

A proposta de Mouritsen, nesse contexto revisionista, é estudar o liberto como uma categoria sui generis da sociedade romana, que não pode ser enquadrada num modelo de mobilidade social típico da época industrial moderna. É o passado servil que determina o lugar social do liberto, isto é, a libertação do escravo apresenta-se, acima de tudo, como uma reconfiguração das relaçóes de dependência servis no interior da casa senhorial, e isto seria um dado estrutural da sociedade romana, valendo para um largo espectro de tempo, da Segunda Guerra Púnica ao início do século III d.C. Nesse sentido, para o autor, seria inapropriado falar em "independência” ou "ascensão social" dos libertos, como se observa numa vertente modernista de interpretação da economia antiga.

Para demonstrar sua tese, Mouritsen parte do princípio de que libertas/servitus era a distinção básica no desenvolvimento histórico de Roma e ambos os status eram definidos como naturais. Logo, a manumissão causaria um problema, pois significava a transição de uma categoria supostamente natural para outra, seu oposto. Era necessário então regular e conduzir esse processo de transição, no nível prático e ideológico, para manter a validade daquela distinção. No tocante ao primeiro nível, os procedimentos formais de manumissão - manumissio vindicta, censu, e testamento — representariam a ficção de restituição do estado natural de liberdade a um indivíduo erroneamente escravizado. Do ponto de vista ideológico, tratava-se de lidar com o estereótipo de que alguém submetido à escravidão passava por uma degradação social que o maculava e infantilizava doravante. Nos termos de Orlando Patterson (Slavery and social death: a comparative study. Massachusetts: Harvard University Press, 1982), que Mouritsen acompanha de perto, a "morte social" do escravo aparece como insuperável, resultado da violação do corpo servil. A alternativa era explicar a manumissão como um processo de recuperação/melhoramento daqueles escravos que se mostrassem aplicados e leais. Seria como uma recompensa para escravos que estivessem dispostos a “crescer". Essa estratégia ideológica colocava, contudo, a questão da tutela dos libertos na prática.

Para Mouritsen, a relação entre patronos e libertos era muito mais pautada por convençóes informais do que por direitos dos patronos legalmente definidos. Predominava uma postura paternalista da parte do patrono que tratava o liberto como quase um filho, não existindo no interior da família um repúdio à relação com subalternos. E, dentre os modos de controle informal, contava sobretudo um discurso, que atravessa as fontes literárias, acerca do "bom" e do "mau" liberto, que buscava designar ao ex-escravo seu lugar na sociedade e na família. Isto não significava que inexistissem tensões decorrentes de dissonâncias de status causadas por libertos que se destacassem por seu poder ou riqueza, como reconhece o autor quando trata dos libertos imperiais e dos libertos ricos em Roma. Todavia, esses exemplos não comprometeriam seu modelo de análise, pois representariam na verdade muito mais as transformaçóes polí- 
ticas advindas com o Principado - crise da noção tradicional de libertas e montagem de uma autocracia - do que propriamente uma crise da ideologia subjacente à prática da manumissáo. $\mathrm{O}$ recurso a libertos na administração imperial já tinha antecedentes republicanos, em que a aristocracia servia-se de seus dependentes como auxiliares na gestáo da res publica. E a própria riqueza dos libertos, como transparece nas fontes literárias imperiais, não demonstraria imediatamente um aumento de escala desse fenômeno, mas tão somente que a questão se tornou mais sensível na sociedade imperial, atuando como um parâmetro para se questionar a crescente diferenciação social proporcionada pela montagem do Império.

Como se vê, a preocupação de Mouritsen é frisar que, a despeito das tensóes geradas pela manumissão no tecido social romano, calcado por uma hierarquia em que a relação entre status e honra ocupa um lugar central, em momento algum se observa, na longa duração, uma autonomização dos libertos em face das domus a que estáo ligados, enfraquecendo os vínculos com os patronos. Essa perspectiva é reforçada quando aborda mais detidamente a prática da manumissão em Roma.

Embora reconheça a grande quantidade de libertos na sociedade romana, Mouritsen sustenta que a manumissão não era universal ou automática, mas seletiva. Seu objetivo primevo era manter o ex-escravo no círculo familiar, estendendo sua vida produtiva e mesmo reforçando a dependência, visto que muitos de seus parentes podiam continuar na escravidáo. Essa integração familiar do liberto descarta igualmente a tese de que prevalecia a compra de liberdade pelo escravo e sua consequente substituição com o montante adquirido pelo proprietário na transação. Inclusive a retenção do peculium pelo liberto é interpretada como uma forma de incentivo para que continuasse com o patrono, assumindo negócios conjuntos. Existiria, portanto, certa racionalidade na manumissão ao tomá-la como uma reconfiguraçáo da escravidáo. Desse modo, o autor combate frontalmente a visão de que os libertos constituiriam uma classe comercial, "burguesa", separada e distinta da aristocracia. Treinado pelo senhor, o escravo adquiria habilidades em determinadas tarefas, que depois como liberto continuava a desempenhar. Os libertos ricos seriam aqueles que lograram conseguir maior apoio de seus patronos. Se houve libertos "independentes", eram aqueles cujos patronos morreram, e não os que compraram sua liberdade e avançaram socialmente por conta própria.

Devido a essa integração socioeconômica em estruturas de poder existentes, a vida cotidiana dos libertos em Roma restringia-se à comunidade doméstica em que estavam inseridos, ou, quando muito, ao contato com outros libertos de outras casas. Enfim, teríamos uma "comunidade de libertos", baseada em laços familiares e na experiência pregressa da escravidão, e o futuro econômico do liberto e seus filhos dependeria do apoio dos respectivos patronos.

Traçadas essas linhas de força da narrativa do livro, cabe ressaltar que a visáo da sociedade romana que Mouritsen apresenta está em sintonia com seus trabalhos anteriores, em especial Plebs and politics in the late Roman Republic (Cambridge: Cambridge 
University Press, 2001), em que também defende uma concepção aristocrática da sociedade, que não permite uma plena integração política do povo, em contraposição a um modelo "democrático" da República romana. Nessa obra já questiona a tese de que existiria uma camada politicamente ativa da plebe composta por libertos independentes. Para Mouritsen, tal ideia desconsidera que "muitos libertos provavelmente possuíam laços bastante estreitos com seus patronos" (Plebs and politics, p. 40).

Contudo, a meu ver, o limite principal de The freedman in the Roman world não reside meramente neste enquadramento da questão dos libertos na estrutura aristocrática da sociedade romana, e sim na falta de uma historicização mais adequada dessa estrutura no contexto da República e, em especial, do Principado. Mouritsen se atém à descrição do que seriam os traços essenciais da prática da manumissão que replicariam aqueles da escravidão como instituição, ou seja, de uma relação tensa entre senhores, que dominam, e escravos, que são dominados. Não por acaso, o pano de fundo teórico do livro é a obra acima citada de Orlando Patterson, que frisa justamente as "características universais da estrutura interna da escravidão", definindo-a como "a dominação permanente e violenta de pessoas desenraizadas e geralmente desonradas" (Slavery and social death, p. 13).

O foco nos elementos essenciais da interação senhor/escravo e patrono/liberto acaba por deixar em segundo plano uma possibilidade de análise que mencione o fato de que - como tem sustentado mais recentemente Joseph Miller (The problem of slavery as his- tory: a global approach. Yale: Yale University Press, 2012) — a escravidão situa-se historicamente em contextos de disputas entre elites por recursos humanos para se afirmarem política e economicamente em suas comunidades. E tanto na República quanto no Principado, a competição aristocrática é uma constante e escravos e libertos — sobretudo aqueles dos imperadores, a denominada Familia Caesaris — desempenham uma função nas disputas por prestígio e poder entre as domus.

Mouritsen até chega a resvalar nesse ponto, quando comenta sobre as "angústias" geradas pela dissonância de status de libertos imperiais ou de libertos ricos. Mas essa explicação de cunho psicológico é uma decorrência de sua abordagem do problema que leva-o a afirmar que a manumissão em Roma apresenta mais continuidades do que rupturas, em sua prática e ideologia, ao longo de quase quatro séculos. A prática pode não ter mudado tanto, mas seus objetivos políticos e econômicos provavelmente oscilaram ao longo do tempo, ao ritmo dos embates sociais em Roma.

Por fim, em que pesem essas considerações, não há como negar que essa obra será doravante um marco nos estudos sobre os libertos em Roma, incentivando novos estudos sobre um tema que diz respeito não apenas a pesquisadores do mundo antigo, mas também àqueles que analisam o escravismo nas Américas.

* Doutor em história pela Universidade de São Paulo, professor adjunto da Universidade Federal de Ouro Preto. Mariana, MG, Brasil. E-mail: joly@uol.com. br. 